\title{
Skull base ligamentous mineralisation: evaluation using computed tomography and a review of the clinical relevance
}

\author{
Philip Touska ${ }^{*}$, Sultana Hasso ${ }^{1}$, Alp Oztek², Fungayi Chinaka ${ }^{1}$ and Steve E. J. Connor ${ }^{1,3,4}$
}

\begin{abstract}
Objectives: To determine the frequency, morphologic and demographic characteristics, and clinical relevance of the mineralisation of six skull base ligaments (interclinoid, caroticoclinoid, petrosphenoid, posterior petroclinoid, pterygospinous, and pterygoalar).
\end{abstract}

Methods: This is a retrospective review of 240 CT scans of the paranasal sinuses (ages 6-80 years). A limited systematic review was performed primarily using Embase and Medline databases.

Results: Ligamentous mineralisation was well delineated on CT and occurred at $\geq 1$ location in $58.3 \%$ of patients. There was a nonsignificant trend towards a greater incidence with advancing age. The interclinoid and posterior petroclinoid ligaments were most commonly mineralised ( $22.1 \%$ and $18.3 \%$, respectively); the petrosphenoid and pterygoalar ligaments were least frequently mineralised (10.8\% and $6.3 \%$, respectively). The mean age of patients with posterior petroclinoid mineralisation was significantly greater than those with interclinoid and petrosphenoid mineralisation and was not seen in patients aged 6-20 years. The literature review highlighted the clinically relevant potential for mineralised ligaments to cause barriers to surgical access (e.g. to the foramen ovale), increase the risk of neurovascular injury during surgery at the skull base (e.g. during anterior clinoidectomy), and predispose to neural impingement.

Conclusions: Skull base ligamentous mineralisation is commonly encountered on CT imaging. Given the potentially significant clinical implications, an understanding of the morphological appearances is of importance to those planning interventions at the skull base. To the authors' knowledge, this study is the first to comprehensively evaluate such a wide range of skull base ligaments using CT. For some ligaments, the incidence on CT has not been previously described.

Keywords: Skull base, Ligaments, Ossification, Pterygoid muscles, Mandibular nerve, Carotid artery, internal

\section{Key points}

- Skull base ligamentous mineralisation is common and seen in most age groups, aside from the posterior petroclinoid ligament, which is has a stronger association with age, reflecting its dural origin.

- Mineralisation of the interclinoid and caroticoclinoid ligaments can increase the risks of several surgical

\footnotetext{
*Correspondence: p.touska@nhs.net

'Department of Radiology, Guy's and St. Thomas' NHS Foundation Trust, 2nd Floor Tower Wing, Guy's Hospital, Great Maze Pond, London SE1 9RT, UK Full list of author information is available at the end of the article
}

procedures at the skull base (including during the treatment of aneurysms). Knowledge of such structures is important in operative planning.

- Ossified ligaments have been associated with neural impingement syndromes of the abducens nerve (petrosphenoid ligament), oculomotor nerve (petroclinoid ligament), and mandibular nerve branches (pterygospinous and pterygoalar ligaments).

\section{Introduction}

Several ligaments exist at the skull base, but knowledge of their anatomy is limited amongst clinicians owing to the paucity of coverage in mainstream anatomical texts. 
However, improvements in minimally invasive neurosurgical techniques have made accurate identification of these structures invaluable for surgical planning, particularly when they become mineralised [1-3]. Mineralised ligaments can present barriers to surgical access, alter the appearances of familiar anatomical landmarks, or prevent structural mobilisation during surgery, thereby increasing the risk of neurovascular injury [4-6]. Additionally, mineralised skull base ligaments have been implicated in neural impingement syndromes as a result of mechanical compression of nerves against ossified bars or within the foramina that mineralised ligaments may form [7-11]. Hence, skull base ligamentous ossification is relevant to radiologists, neurologists, and neurosurgeons managing patients with skull base pathology.

The available literature is predominantly derived from studies of dry skulls, with only a minority using imaging to evaluate these structures (see the tabulated summary of the subsequent systematic review). To the authors' knowledge, this represents the first comprehensive study to use computed tomography (CT) to systematically evaluate the frequency of incidental skull base ligamentous mineralisation in a modern ethnically diverse population.

\section{Materials and methods}

Institutional approval was obtained, and the requirement for informed consent waived. A retrospective review of high-resolution, non-contrast CT studies of the paranasal sinuses (scanned between April 2014 and January 2017) was carried out. Consecutive cases were selected until equal numbers were achieved for each of 15 age groups (range 6-80 years). Scanning took place on a variety of systems, including SOMATOM Definition Edge (Siemens Healthcare, Erlangen, Germany), iCT, and Brilliance 40 (Philips Medical Systems, Eindhoven, Netherlands) scanners using a $\mathrm{kVp}$ of $120 \mathrm{kV}$, mAs of $25-50$, minimum collimation of $0.6-0.625 \mathrm{~mm}$, and a pitch of $0.624-0.8$. Each imaging study was evaluated by there independent observers $\mathrm{PT}, \mathrm{SH}$, and $\mathrm{FC}$, and the presence of mineralisation (calcification or ossification) for the six skull base ligaments was recorded. Initial detection was carried out by analysing thin axial reconstructions, and detailed evaluation of morphology was carried out using multiplanar reconstructions. The ligaments examined, their anatomical courses, and planes used to evaluate them on CT are detailed in Table 1. Examples of the appearances of the ligaments on CT are demonstrated in Figs. 1, 2, and 3.

In each case, mineralisation was considered 'partial' if it extended from 50 to $<100 \%$ of the ligament's length and 'complete' if it extended to involve the entire length of the ligament. The so-called contact type of mineralisation, where a subtle suture line may be seen at the midpoint of an osseous bar, was considered complete for the purposes of this study [12]. If complete mineralisation resulted in the formation of a foramen, the thickness of the bony bar (at its midpoint) and the corresponding foraminal area were measured using double oblique sagittal reformats on a PACS workstation using syngo.via software (Siemens Healthcare, Erlangen, Germany). Ligaments with $<50 \%$ mineralisation, including small bony spurs, were excluded. The use of $50 \%$ was chosen as it was felt to be both clinically relevant and simpler to facilitate reproducibility; it has also been employed in prior studies of ligamentous mineralisation $[18,23]$. In the case of interobserver discordance, an agreement was achieved through consensus. Where available, demographic information was recorded.

Statistical testing of multiple correlated samples was carried out using a one-way ANOVA with post hoc analysis using the modified Tukey method and two-tailed $t$

Table 1 Ligament characteristics

\begin{tabular}{|c|c|c|}
\hline Ligament & Course & Plane used for evaluation \\
\hline Interclinoid ligament & $\begin{array}{l}\text { Extends between the anterior and posterior clinoid processes (or occasionally } \\
\text { middle and posterior clinoid processes). When completely mineralised, it can } \\
\text { form a common interclinoid foramen }[12,13] \text {. }\end{array}$ & Double oblique sagittal \\
\hline $\begin{array}{l}\text { Caroticoclinoid (anterior } \\
\text { interclinoid) ligament }\end{array}$ & $\begin{array}{l}\text { Extends between the anterior and middle clinoid processes. When completely } \\
\text { mineralised, it forms the clinocarotid canal traversed by the ICA }[12,14]\end{array}$ & Double oblique axial \\
\hline $\begin{array}{l}\text { Petrosphenoid (Grüber's) } \\
\text { ligament }\end{array}$ & $\begin{array}{l}\text { Extends from the petrous tubercle (medial to the trigeminal impression) at the } \\
\text { petrous apex to the lower aspect of the posterior clinoid process [15-17]. }\end{array}$ & Double oblique sagittal \\
\hline $\begin{array}{l}\text { Posterior petroclinoid } \\
\text { ligament }\end{array}$ & Extends from the petrous ridge to the posterior clinoid process $[18,19]$. & Double oblique sagittal \\
\hline $\begin{array}{l}\text { Pterygospinous (Civinini) } \\
\text { ligament }\end{array}$ & $\begin{array}{l}\text { Extends from the spine of the sphenoid to the posterior aspect of the lateral } \\
\text { pterygoid plate. When completely mineralised, it forms the foramen of Civinini } \\
\text { [20-22]. }\end{array}$ & Double oblique sagittal \\
\hline $\begin{array}{l}\text { Pterygoalar (Hyrtl-Calori or } \\
\text { 'innominate') ligament }\end{array}$ & $\begin{array}{l}\text { Extends from the root of the lateral plate of pterygoid process to the infratemporal } \\
\text { surface of the greater sphenoid wing, lateral to the foramen spinosum. Historically, } \\
\text { complete mineralisation of the pterygoalar ligament was termed the porus } \\
\text { crotaphiticobuccinatorius of Hyrtl (derived from the historic term for the mandibular } \\
\text { nerve with deep temporal_or crotaphitic_-and buccinator branches) [20-22]. }\end{array}$ & Double oblique sagittal \\
\hline
\end{tabular}




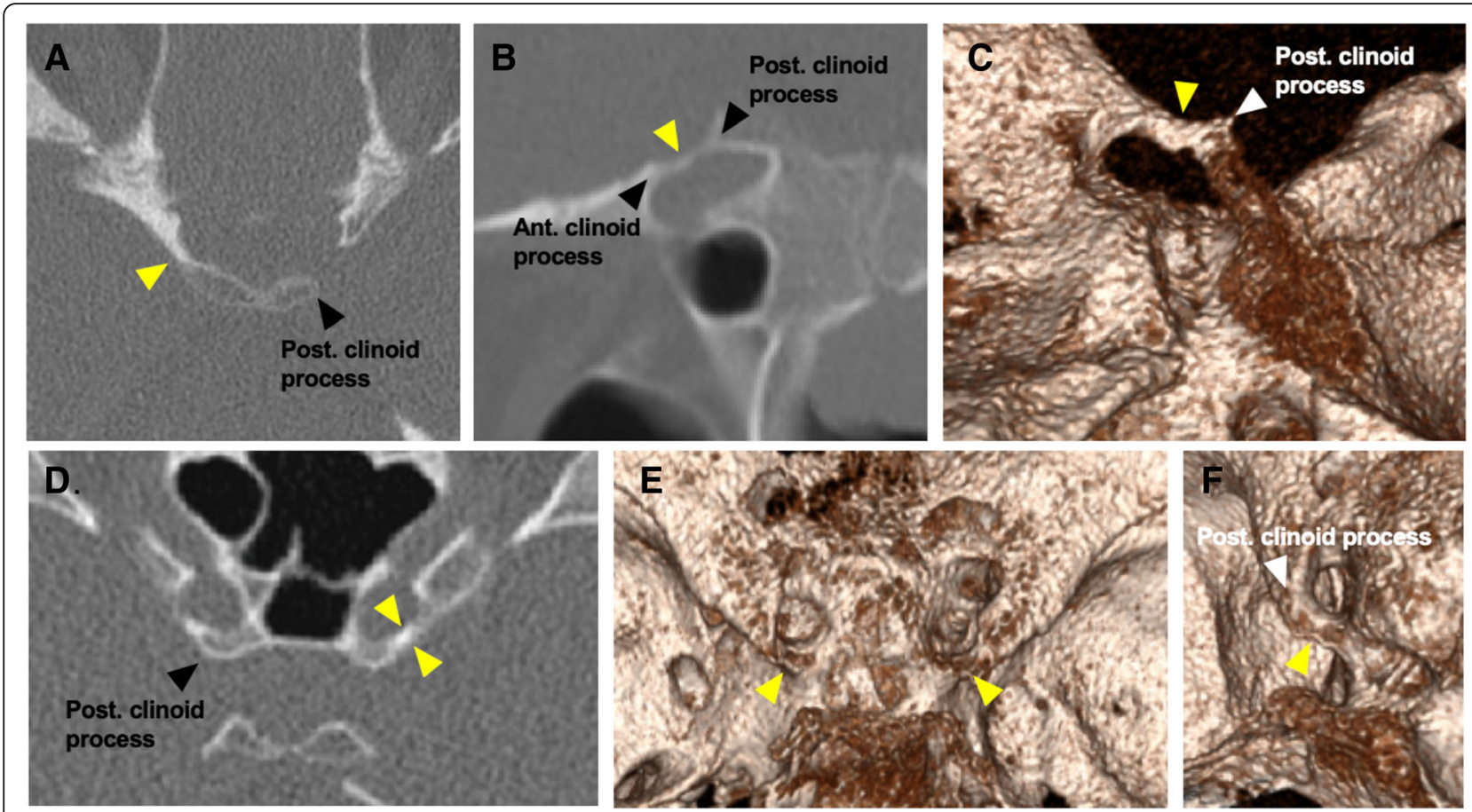

Fig. 1 Mineralised caroticoclinoid and interclinoid ligaments. Axial (a), sagittal oblique (b), and 3D (c) volume reconstruction demonstrating a complete interclinoid ligament on the right (yellow arrowhead). Axial CT (d) and 3D (e) volume reconstructions demonstrating bilateral complete caroticoclinoid ligaments (yellow arrowheads). f 3D reconstruction demonstrating the right-sided complete caroticoclinoid ligament (yellow arrowhead)
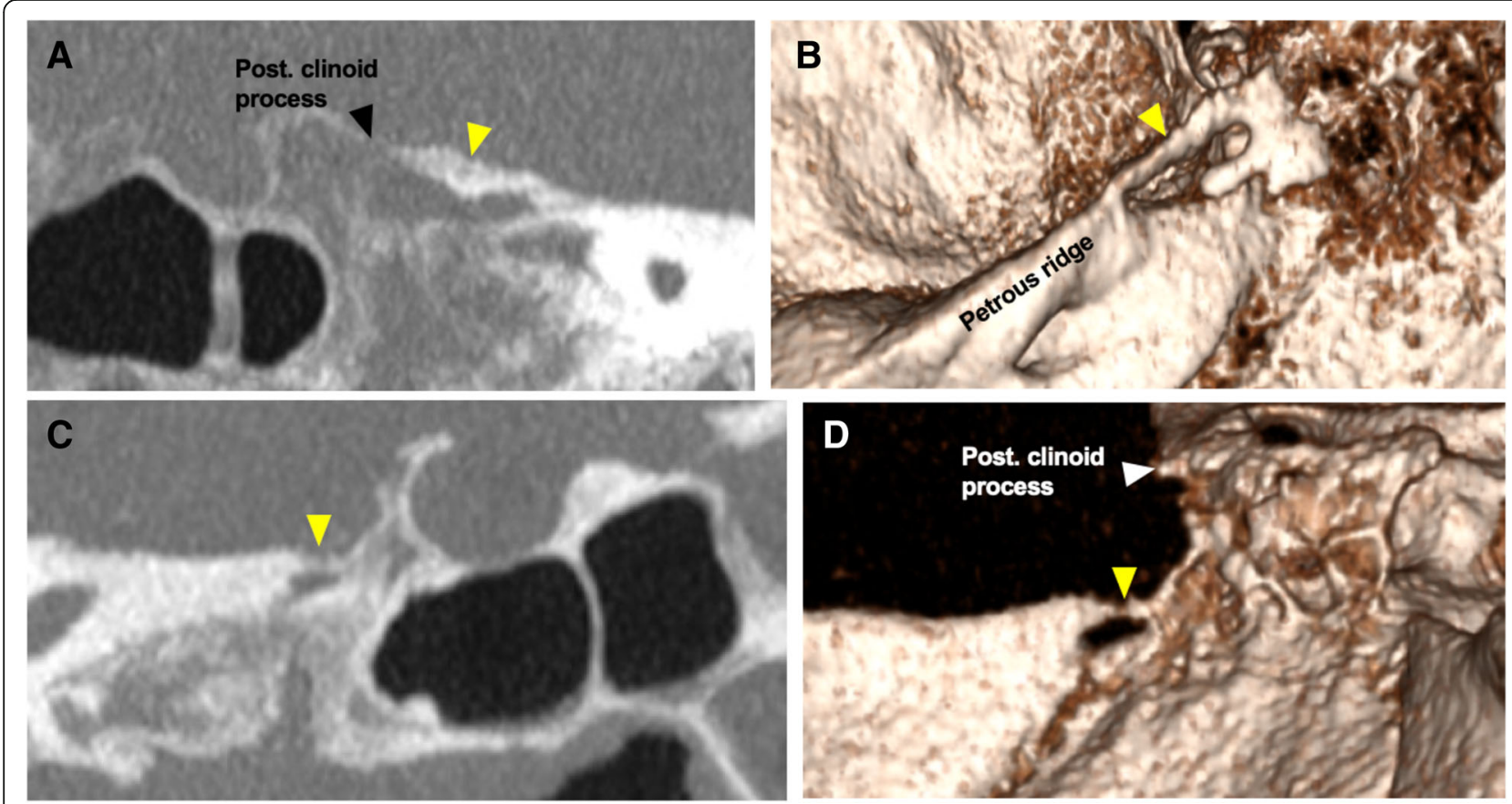

Fig. 2 Mineralised posterior petroclinoid and petrosphenoid ligaments. a Oblique-sagittal maximum-intensity projection (MIP). b 3D volume reconstruction of a right-sided, completely mineralised posterior petroclinoid ligament (or dural fold) (yellow arrowhead). c Oblique-sagittal maximum-intensity projection (MIP). d 3D volume reconstruction of a right-sided, complete petrosphenoid bar (yellow arrowhead) 

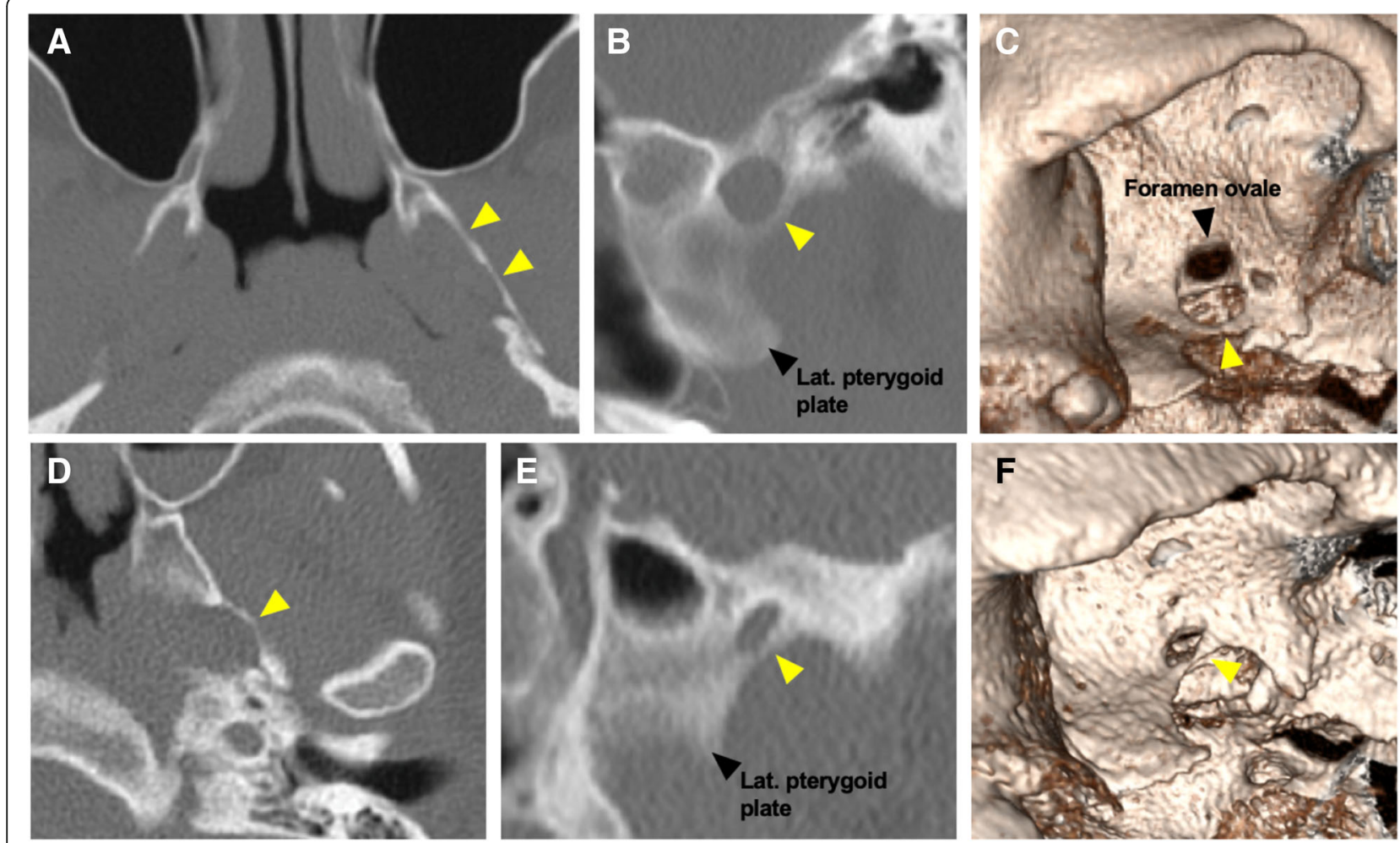

Fig. 3 Mineralised pterygospinous and pterygoalar ligaments. Axial (a), oblique sagittal MIP (b), and 3D (c) volume CT reconstructions demonstrating a completely mineralised left pterygospinous ligament (yellow arrowheads). The foramen ovale is demonstrated on the 3D reconstruction. Axial (d), oblique sagittal MIP (e), and 3D (f) volume $C T$ reconstructions demonstrating a completely mineralised left pterygoalar ligament (yellow arrowheads). The foramen ovale is obscured

testing, and the chi-squared test was employed to analyse the distribution of categorical variables using Vassarstats [24] and Microsoft Excel ${ }^{\circ}$ (Redmond, WA); a $p$ value of $<0.05$ was deemed to be significant.

A systematic review of the English language literature was carried out as per PRISMA [25] guidelines using Embase and Medline databases primarily with additional studies identified through study references and a limited search using Google Scholar. The following search terms were utilised 'interclinoid', 'caroticoclinoid', 'sellar bridge', 'petrosphenoid,' 'petroclinoid, 'pterygospinous' 'Civinini + ligament', 'pterygoalar,' 'Hyrtl + ligament', and 'crotaphitico-buccinatorius'. Studies were excluded if they were deemed irrelevant (e.g. pertaining to other parts of the body). Selected case reports were included if a potentially clinically consequential observation was documented.

\section{Results}

\section{Demographics}

A total of 240 CT studies were reviewed comprising 121 female $(50.4 \%)$ and 119 male $(49.6 \%)$ patients. The patients were divided into 15 groups according to age, with each group spanning 5 years (e.g. 6-10 years). The average age was 42.7 years (range $6-80$ years). The majority of patients were white British/European $(62.5 \% ; n=150)$ followed by black British/African and Caribbean (18.3\%; $n=44)$, Southeast Asian (Indian subcontinent) (11.3\%; $n$ =27), and a group comprising Middle Eastern, East Asian (Chinese), mixed ethnicity, and other/unknown ethnicity $(7.9 \% ; n=19)$.

Partially or completely mineralised skull base ligaments in at least one location were found in $58.3 \%$ of patients $(n=140)$.

Mineralisation was observed in all age groups, but least frequently amongst the 16-20 years age group (31\%) and most frequently in the 56-60 years age group (81\%) Fig. 4. Dividing the population into 5 larger groups of $48 \mathrm{pa}$ tients, each revealed lower mean proportions of mineralised ligaments amongst the 6-20 and 21-35 years groups compared with older patients. Although the difference was nonsignificant ( $p=0.0795$, using a one-way ANOVA test), there was a trend towards increasing mineralisation with age. Additionally, the rate of complete mineralisation (patients with $\geq 1$ completely ossified bar on either side) showed increasing frequency with age Fig. 5. The mean proportion of patients with at least 1 completely ossified ligament $(n=53)$ were as follows: $6-20$ years $=4 \%, 21-35$ years $=9 \%, \quad 36-50$ years $=11 \%, \quad 51-65$ years $=16 \%$, and 


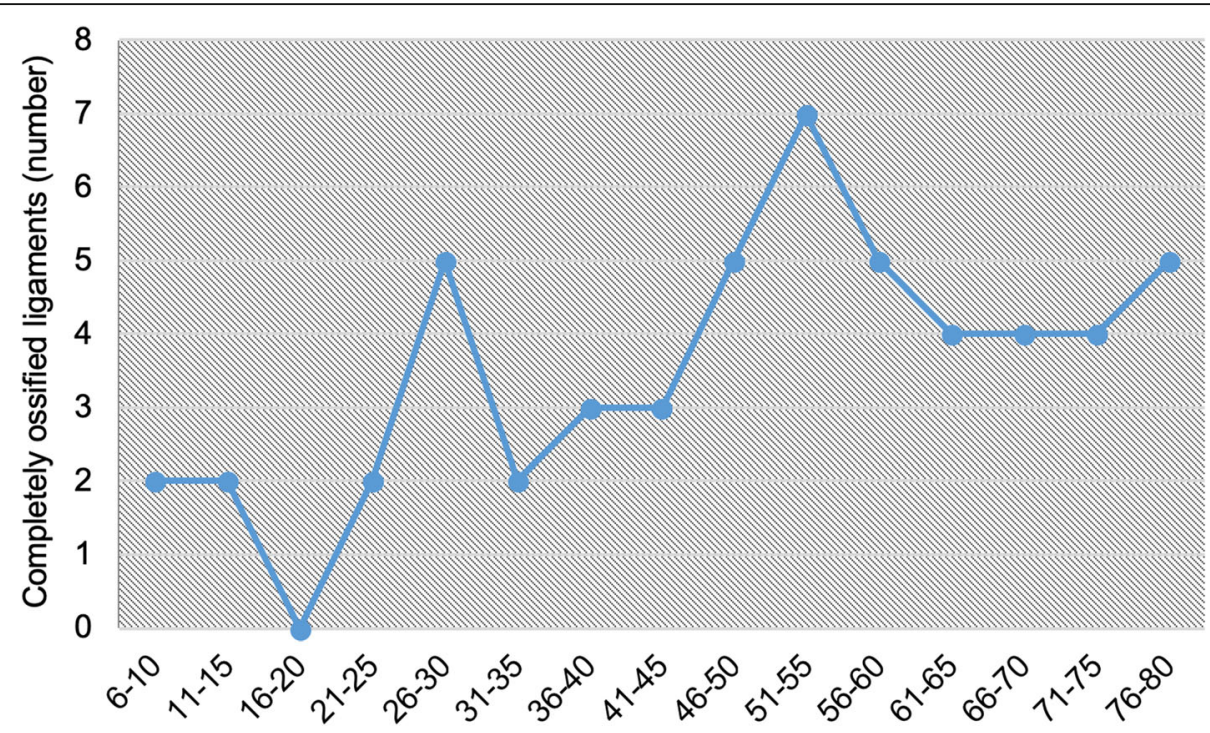

Fig. 4 Frequency of complete ligament ossification amongst different age groups

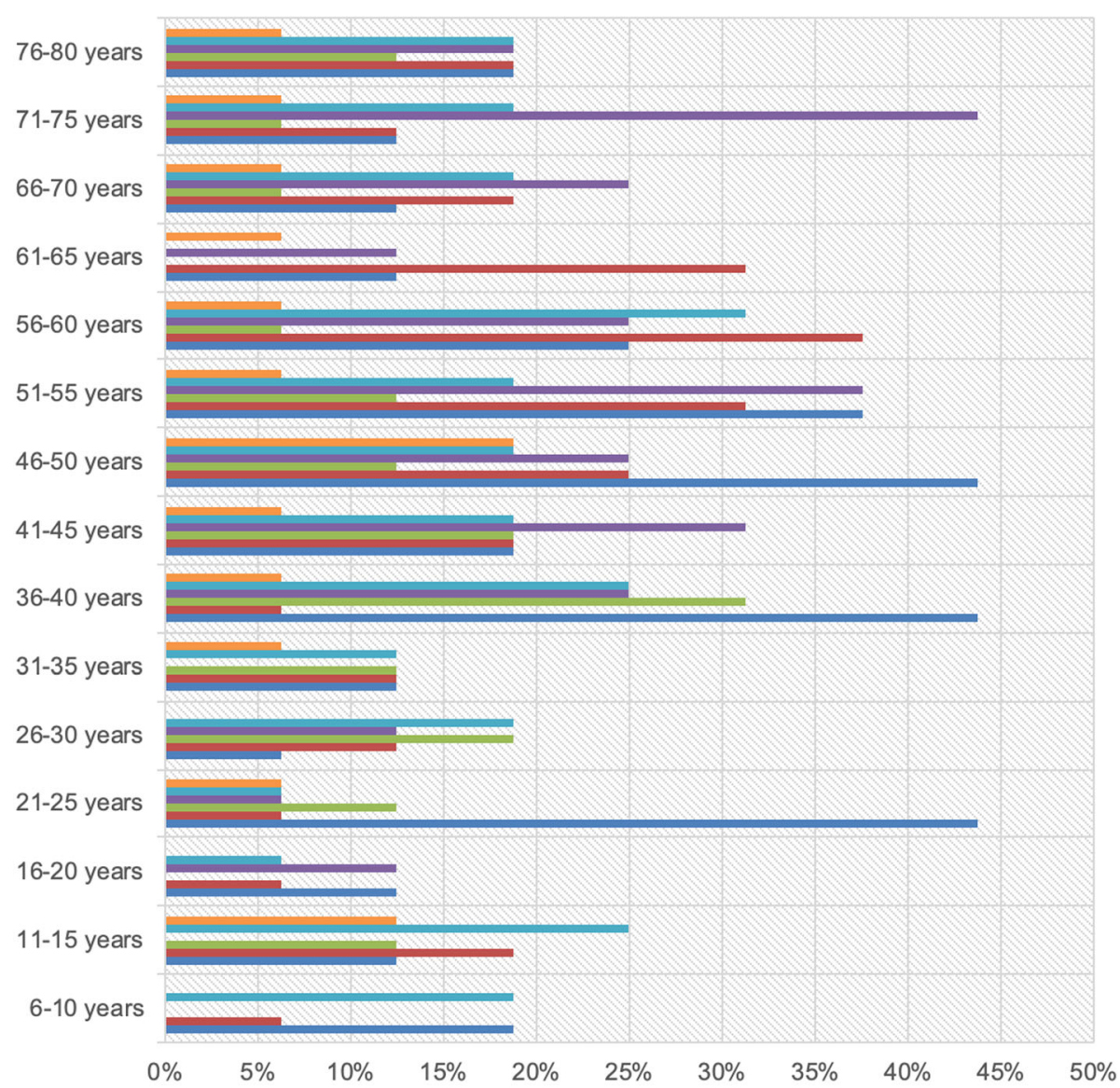

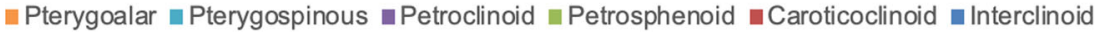

Fig. 5 Ligament ossification by type and age group 
$66-80$ years $=13 \%$. The difference between the means was significant (one-way ANOVA: F-ratio $=4.06 ; p=0.0329$ ); however, on breakdown of the differences between the means using the Tukey method, only the difference between the 6-20 year and 51-65 year groups was found to be statistically significant $(p=<0.05)$.

The proportion of patients with mineralised ligaments was highest amongst those of white British/European heritage, followed by black British, African, and Caribbean heritage (57\%) and those of British Asian/Southeast Asian heritage (52\%). The lowest proportion was seen amongst those of other heritages. However, the difference between the proportions of ossified ligaments amongst white and black and white and Southeast Asian patients was nonsignificant $(p=0.635$ and $p=0.382$, respectively, using a chi-squared test).

Overall, there was a very slight male preponderance for ligamentous mineralisation with 74 males and $66 \mathrm{fe}-$ males $(\mathrm{M}: \mathrm{F}=1.12: 1)$.

\section{Ligament type}

The incidence of ligamentous ossification (both partial and complete) varied according to the ligament type, with the interclinoid ligament being most commonly identified and the pterygoalar ligament least commonly identified (the proportions for all ligaments are detailed in Table 2).

The majority (four of six) of mineralised ligaments were more commonly unilateral, but the caroticoclinoid and petroclinoid ligaments were more commonly bilateral. The proportions of bilaterally and unilaterally mineralised ligaments are detailed in Table 3.

Mineralised interclinoid and caroticoclinoid ligaments could be seen in all age groups. However, the remaining ligament types were not present in all age groups; for example, mineralised petrosphenoids were not encountered in the 6-10 and 16-20 year groups. The frequencies of each ligament type amongst the various age groups are depicted in Fig. 3.

Overall, there was no statistically significant difference between the mean ages of patients with mineralised ligaments (0.0777, using a one-way ANOVA test); however, breakdown analysis of the differences between the

Table 2 Ossification of ligament types (in descending order of frequency)

\begin{tabular}{lll}
\hline & Total $(n)$ & Proportion (\%) \\
\hline Interclinoid & 53 & 22.1 \\
Petroclinoid & 44 & 18.3 \\
Caroticoclinoid & 42 & 17.5 \\
Pterygospinous & 41 & 17.1 \\
Petrosphenoid & 26 & 10.8 \\
Pterygoalar & 15 & 6.3 \\
\hline
\end{tabular}

groups revealed a significantly higher mean age for patients with posterior petroclinoid ligamentous mineralisation compared to those with interclinoid and petrosphenoid mineralisation $(p=0.004$ and $p=0.009$, respectively).

The thickness of the mineralised ligaments varied slightly, with the thinnest being the pterygospinous (Table 4). The smallest foramen was formed by the mineralised petrosphenoid ligament, and the largest foramen was formed by the mineralised interclinoid ligament (Table 4).

\section{Multiple ligaments}

Ossification of multiple (>1) ligament types was observed in $26.7 \%(n=64)$ patients. The majority $(76.6 \% ; n$ $=49$ ) of these patients had a combination of two ossified ligaments, with the interclinoid and caroticoclinoid ligaments in combination $(n=20)$ and the petroclinoid and pterygospinous ligaments in combination $(n=11)$ being the most common. Ossification of $>2$ ligament types was seen in $23.4 \%(n=15)$ of patients and ossification of $>3$ ligament types in $3.1 \%(n=2)$ of cases.

\section{Limited systematic review}

Screening yielded 492 abstracts in the initial search; however, following the removal of duplicates and studies that did not meet the inclusion criteria, 61 records remained for inclusion (Table 5).

\section{Discussion}

Mineralisation of skull base ligaments can occur as a result of an interplay between a broad range of factors, including genetics, metabolic abnormalities, and mechanical stress [68]. Such factors may explain de novo mineralisation later in life. However, the presence of ligamentous skull base mineralisation in children without an obvious inductive stimulus [12] may reflect developmental variation, which some have termed atavistic (i.e. representing evolutionary remnants) owing to the presence of similar ossified structures in non-human species [69].

It is clear from this study that mineralisation of skull base ligaments is a common finding (58.3\%). In keeping with a suspected predominantly developmental origin, mineralisation was present in all age groups, although there was a nonsignificant trend towards an increased incidence with age. The association was however stronger for complete ligamentous mineralisation and varied with ligament type. In particular, the mean age of patients with posterior petroclinoid ligamentous mineralisation was higher than those with interclinoid or petrosphenoid mineralisation and was not observed in individuals aged 6-15 and 31-35 years. This finding likely reflects the nature of the posterior petroclinoid ligament, which is in fact a fold of dura mater (rather 
Table 3 Characteristics of mineralised ligaments

\begin{tabular}{|c|c|c|c|c|c|c|c|c|c|}
\hline & \multicolumn{5}{|c|}{ Bilateral } & \multicolumn{4}{|c|}{$\underline{\text { Unilateral }}$} \\
\hline & \multicolumn{2}{|l|}{ Total } & \multirow{2}{*}{$\begin{array}{l}\text { Complete } \\
(\%)\end{array}$} & \multirow{2}{*}{$\begin{array}{l}\text { Mixed* } \\
(\%)\end{array}$} & \multirow{2}{*}{$\begin{array}{l}\text { Partial } \\
(\%)\end{array}$} & \multicolumn{2}{|l|}{ Total } & \multirow{2}{*}{$\begin{array}{l}\text { Complete } \\
(\%)\end{array}$} & \multirow{2}{*}{$\begin{array}{l}\text { Partial } \\
(\%)\end{array}$} \\
\hline & $\%$ & $n$ & & & & $\%$ & $n$ & & \\
\hline Interclinoid & 45.3 & 24 & 29.2 & 12.5 & 58.3 & 54.7 & 29 & 20.7 & 79.3 \\
\hline Caroticoclinoid & 59.5 & 25 & 60.0 & 24.0 & 16.0 & 40.5 & 17 & 52.9 & 47.1 \\
\hline Petrosphenoid & 26.9 & 7 & 14.3 & 0.0 & 85.7 & 73.1 & 19 & 26.3 & 73.7 \\
\hline Petroclinoid & 56.8 & 25 & 4.0 & 4.0 & 92.0 & 43.2 & 19 & 10.5 & 89.5 \\
\hline Pterygospinous & 34.1 & 14 & 7.1 & 42.9 & 50.0 & 65.9 & 27 & 14.8 & 85.2 \\
\hline Pterygoalar & 20.0 & 3 & 33.3 & 66.7 & 0.0 & 80.0 & 12 & 16.7 & 83.3 \\
\hline
\end{tabular}

*Mixed cases were those in which where complete mineralisation occurred only on one side

than a true ligament) that arises from the fixed portions of the tentorial incisura, and calcification of the dura is generally rarely seen in children $[18,19,70]$. There was no significant difference in the rate of ligamentous mineralisation amongst the largest ethnic groups included within the study; however, variance exists in the literature with higher rates of observed mineralisation in some (particularly Greek) populations, suggesting a potential genetic predisposition [14, 30, 57].

\section{Interclinoid and caroticoclinoid ligaments}

Mineralised of these 'sellar bridges' was relatively commonly encountered within the studied population $(22.1 \%$ and $17.5 \%$, respectively). Whilst the incidence of caroticoclinoid mineralisation reflects the majority of prior studies $(12-35.67 \%[2,3,5,6,8,12,26-29,31-37])$, there were some outliers $[14,30]$. The incidence of interclinoid ligamentous mineralisation was higher in the current study than in many prior studies $(4-11.8 \%$ [2, $12,26,27,29,36,37,39]$ ), which may be secondary to the relatively long and exposed nature of the interclinoid ligament that could make it vulnerable to loss during the preparation of dry skulls. Indeed, a large Italian study of 300 CT scans of the head recorded incidences closer to the current study; furthermore, it corroborated our observation that mineralisation of the caroticoclinoid and interclinoid ligaments is not infrequently associated [32].

The clinical significance of mineralised interclinoid and caroticoclinoid ligaments arises primarily from their close relationships with the paraclinoid internal carotid artery (with the caroticoclinoid ligament potentially forming a solid ring around it) and cavernous sinus. In particular, the presence of ossified bars in these locations can make the extradural removal of the anterior clinoid process during clipping of paraclinoid aneurysms extremely difficult, requiring increased drilling and manipulation, which is accompanied by an increased potential risk of carotid rupture $[2,5,14,26,31,71]$. Furthermore, these structures can complicate the excision of central skull base tumours where the internal carotid artery and cavernous sinus require exposure [2]. In addition, the presence of a completely mineralised caroticoclinoid ligament may alter the appearance of the middle clinoid process, which can be used as landmark for the anteromedial roof of the cavernous sinus and transition between the cavernous and clinoid segments of the internal carotid artery during endoscopic endonasal approaches to the pituitary gland $[5,6]$. Furthermore, the presence of high-density calcification in the parasellar region may cause confusion on CT angiography if the viewer is unfamiliar with skull base ligamentous mineralisation; indeed, mineralisation of the interclinoid has been confused with para-posterior communicating artery aneurysm [38]. Finally, 'sellar bridges' have been associated with dental and other developmental abnormalities, including Gorlin-Goltz syndrome $[26,40,42,72,73]$.

Table 4 Ligament thickness and foramen size

\begin{tabular}{|c|c|c|c|c|c|}
\hline & \multicolumn{2}{|c|}{ Ligament thickness } & \multicolumn{3}{|c|}{ Mean foramen size } \\
\hline & Mean $(\mathrm{mm})$ & $\overline{\mathrm{SD}(\mathrm{mm})}$ & Mean $\left(\mathrm{mm}^{2}\right)$ & $\mathrm{SD}\left(\mathrm{mm}^{2}\right)$ & Range $\left(\mathrm{mm}^{2}\right)$ \\
\hline Interclinoid & 1.8 & 0.5 & 75.2 & 22 & $43-142$ \\
\hline Caroticoclinoid & 1.8 & 0.8 & 25.3 & 4.4 & $24-40$ \\
\hline Petrosphenoid & 1.1 & 0.5 & 7.2 & 5.5 & $2-18$ \\
\hline Petroclinoid & 1.3 & 0.5 & 39 & 14.5 & $24-60$ \\
\hline Pterygospinous & 0.95 & 0.3 & 39.9 & 32.9 & $2-112$ \\
\hline Pterygoalar & 1.2 & 0.4 & 13.3 & 7.2 & $4-25$ \\
\hline
\end{tabular}




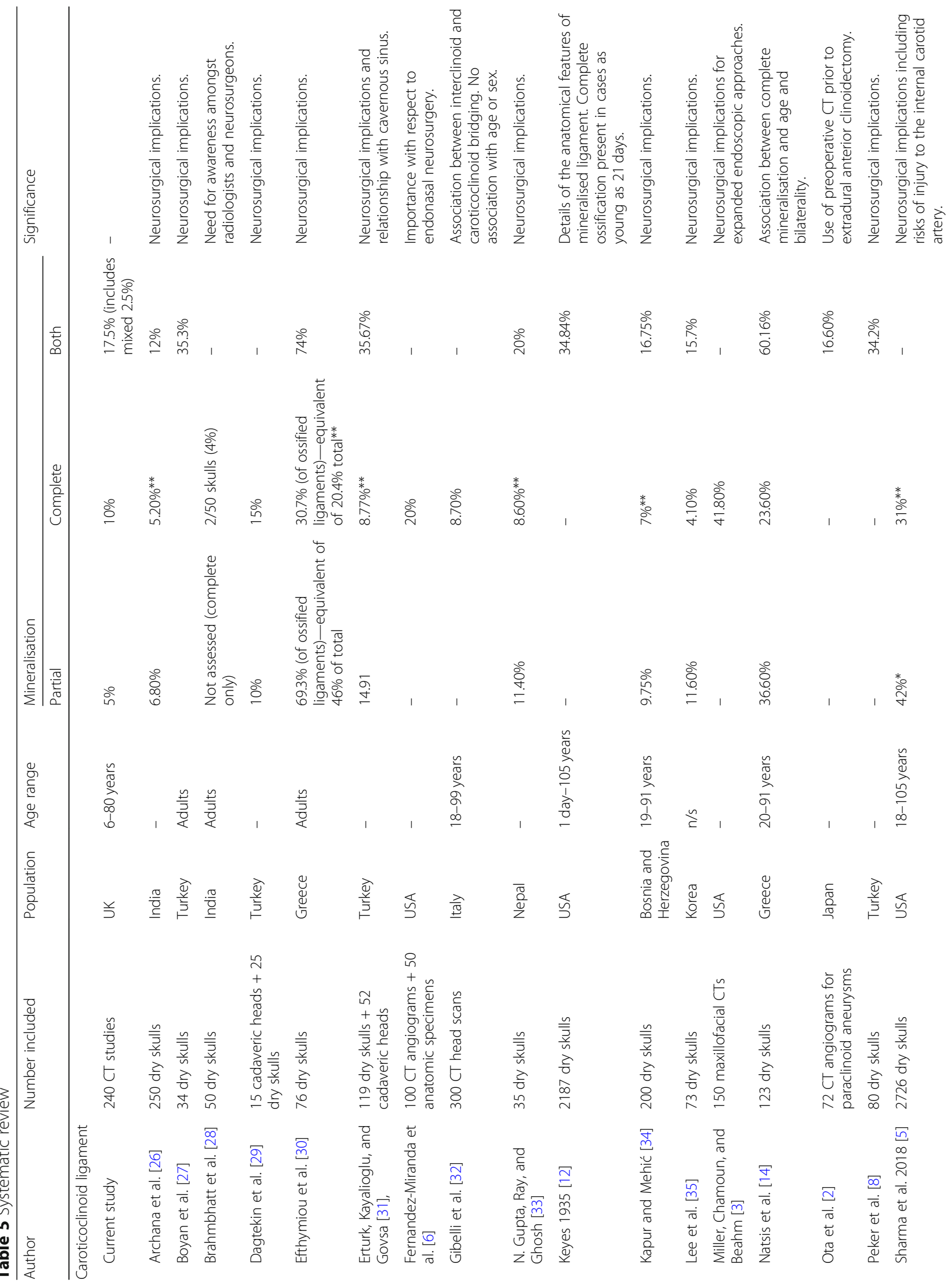




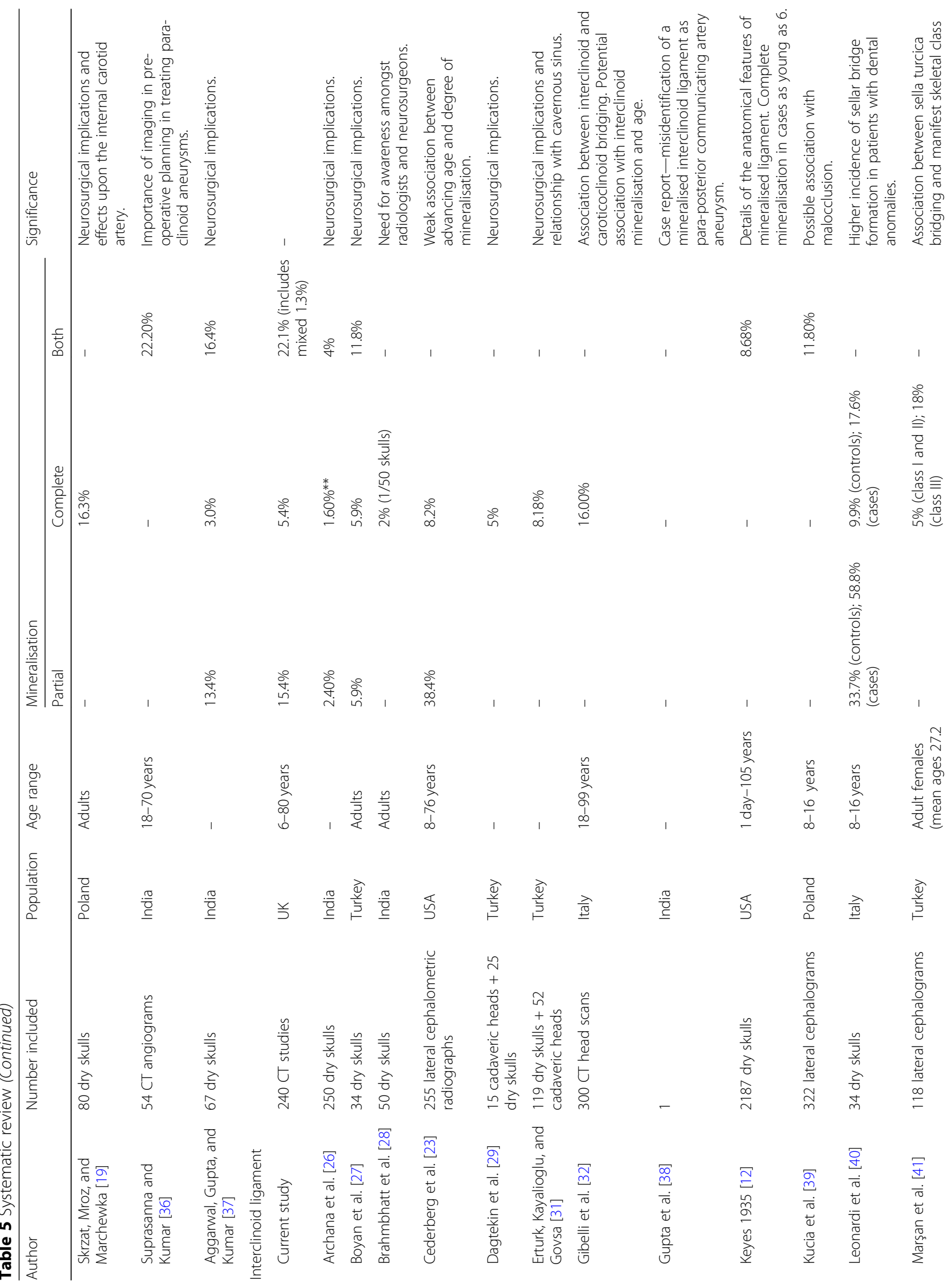


Touska et al. Insights into Imaging (2019) 10:55

Page 10 of 17

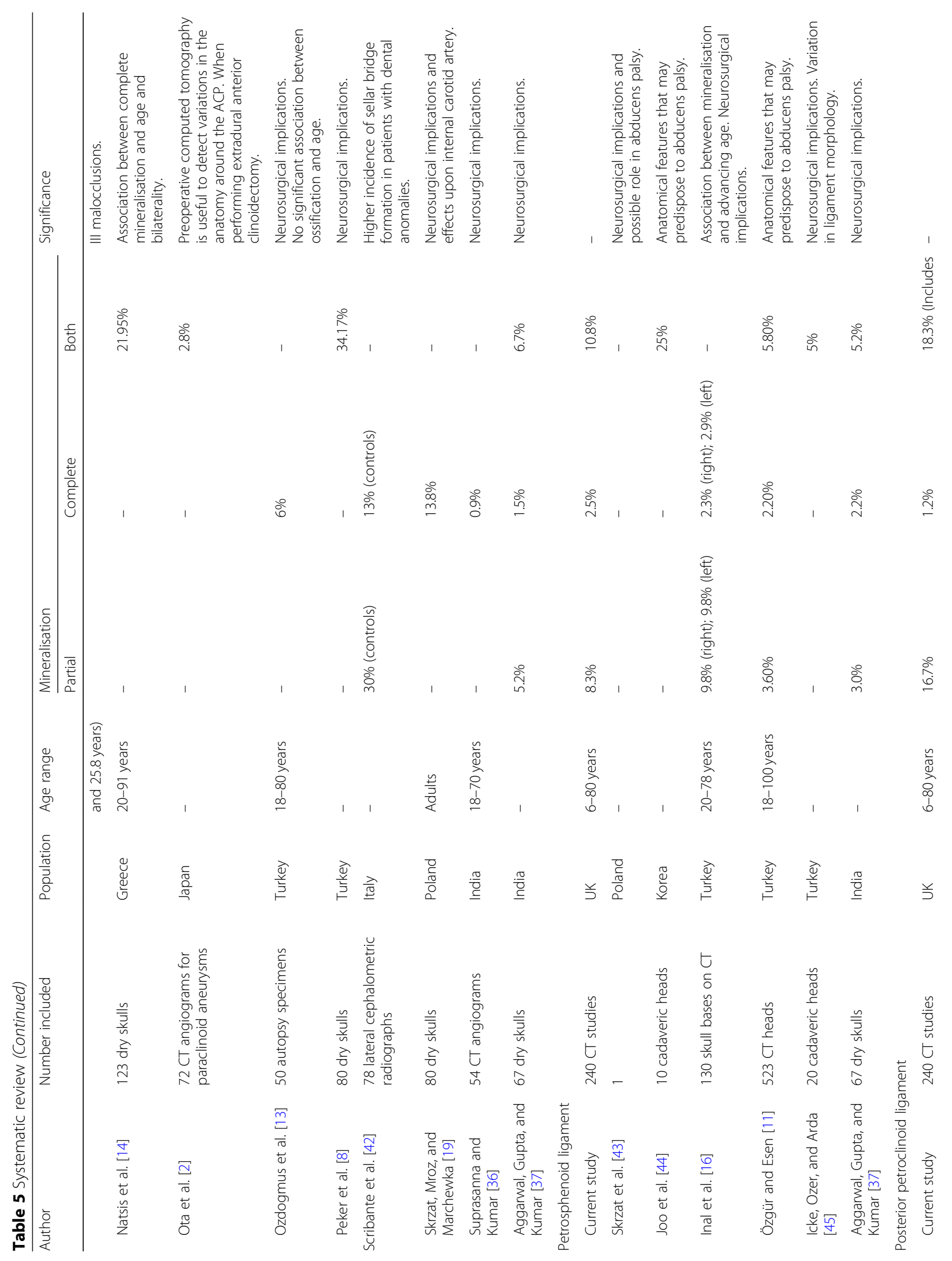




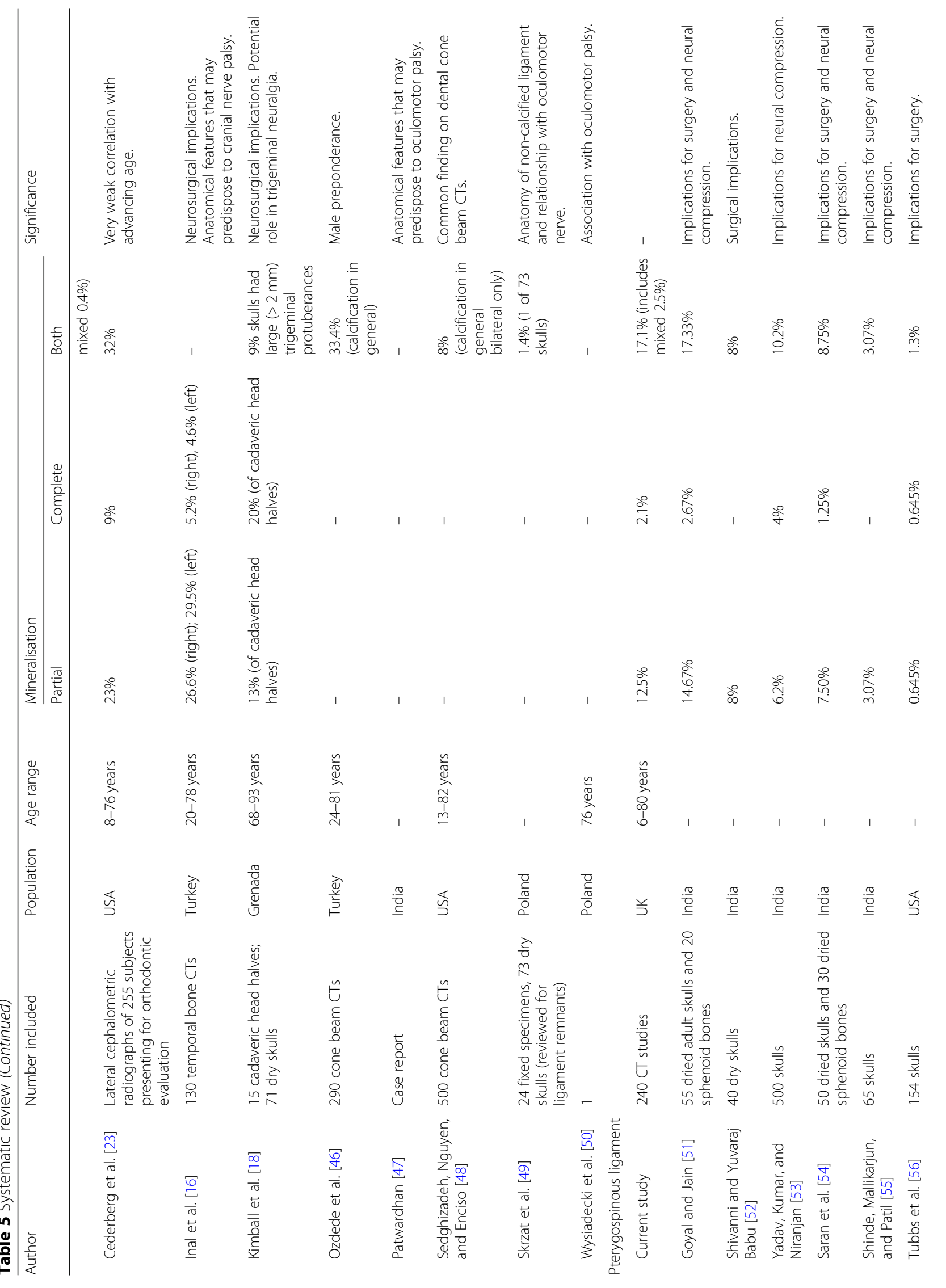




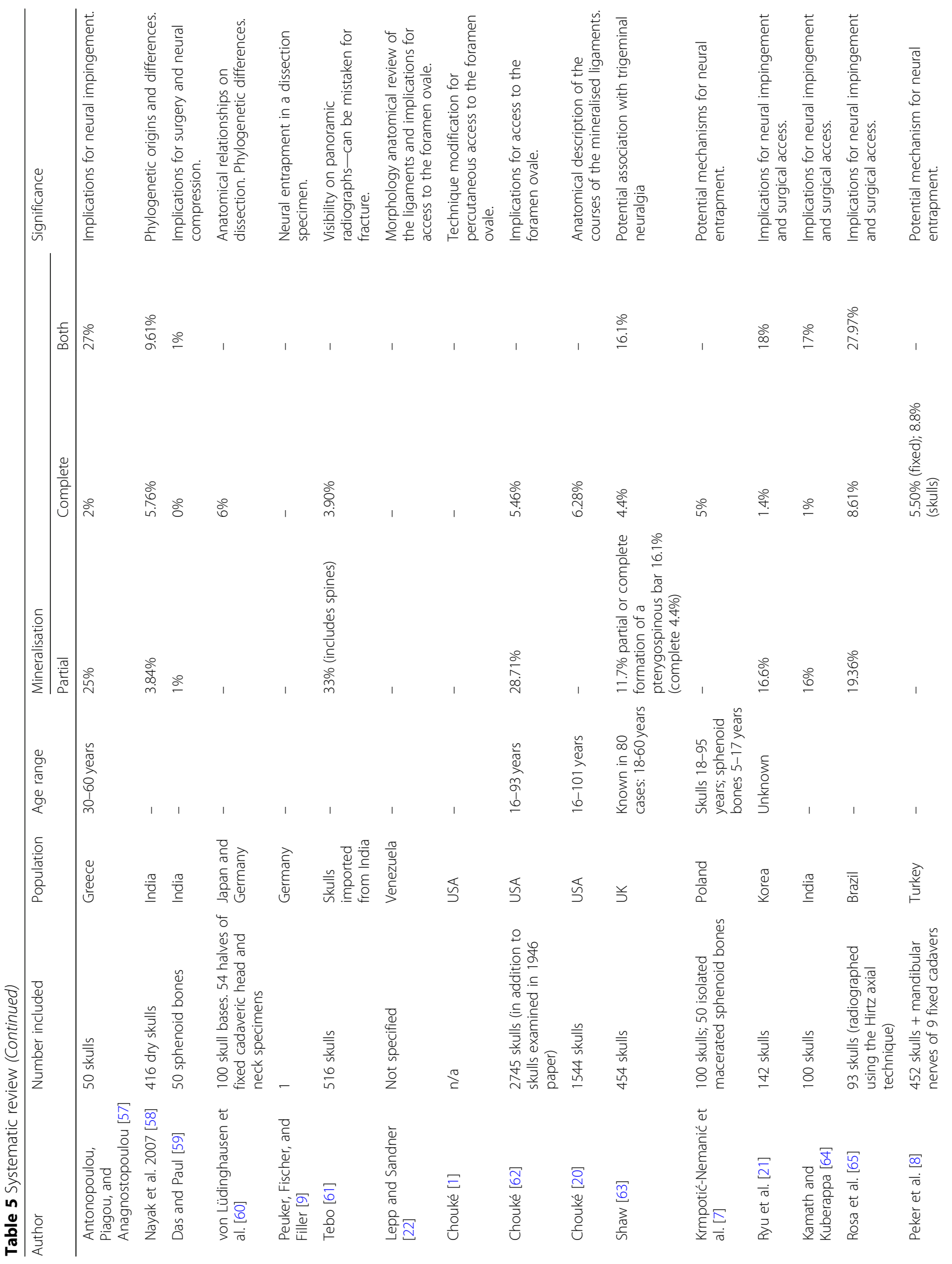




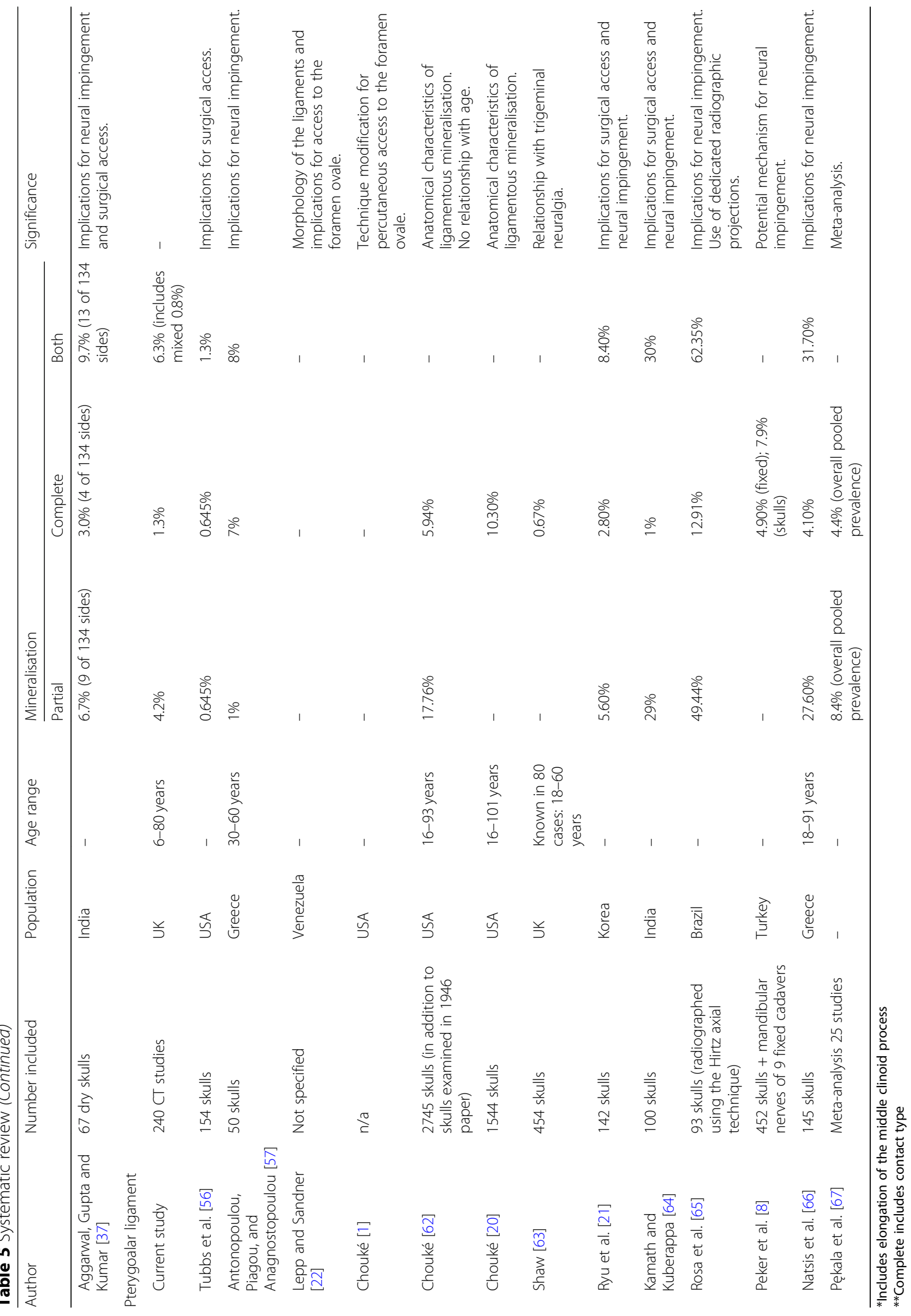




\section{Petrosphenoid ligament}

This structure was amongst the least commonly mineralised skull base ligaments (10.8\%), which is compatible with the published range of $5-25 \%[11,16,37,43-45]$.

The clinical significance of petrosphenoid ligamentous mineralisation principally arises from its close relationship to the abducens nerve, which passes below it within Dorello's canal [17]. For example, in the setting of raised intracranial pressure and uncal herniation, the mineralised ligament may protect the abducens nerve, but may present a noncompliant structure against which the oculomotor nerve may be compressed [16]. Furthermore, the passage of the abducens nerve beneath a densely mineralised ligament is postulated to have a role in abducens nerve palsy as it would create a noncompliant structure around the nerve, which would limit expansion in the setting of neural inflammation [11]. Finally, the petrosphenoid ligament is a helpful landmark during subtemporal-transtentorial-transpetrous approaches to the posterior and middle cranial fossae and its mineralisation may lead to the misidentification of anatomical localisation $[16,74]$.

\section{Posterior petroclinoid ligament (fold)}

This structure was the second most commonly mineralised ligament $(18.3 \%)$, which is higher than some studies of dry skulls $(1.4-9 \%)[18,49]$, but comparable to prior radiographic and CT studies [16, 23, 46]. This likely reflects the superiority of imaging in detecting fine calcified structures that may not be preserved in dry skulls.

The clinical significance of posterior petroclinoid ligament (or dural fold) mineralisation derives from its proximity to neural structures. In particular, in its course between the anterior petrous ridge to the posterior clinoid process, it forms the roof of the porus trigeminus and medial border of the oculomotor trigone (with the oculomotor nerve running over the ligament) [18]. In cases of mineralisation, Wysiadecki et al. found greater fixation of the dural sheath of the oculomotor nerve, which may increase the risk of neural injury during intraoperative manipulation, and prior division with an appropriate instrument may be required $[16,50]$. It may also increase the risk of oculomotor neural injury following relatively insignificant head trauma, as a result of compression of the nerve against a noncompliant ligament $[10,47]$. Finally, there has been speculation that compression of the trigeminal nerve may occur in the setting of an extensively mineralised posterior petroclinoid ligament and may be considered for those in whom prior microvascular decompression has failed $[18,75]$.

\section{Pterygospinous and pterygoalar ligaments}

In the current study, these structures were found to be mineralised in $17.1 \%$ and $6.3 \%$ (pterygospinous and pterygoalar ligaments, respectively) of patients. The published rate of ligamentous mineralisation is variable $(1-27.97 \%$ for the pterygospinous ligament [7, 8, $20,21,51-58,60-65]$ and $1.3-62.35 \%$ for the pterygoalar ligament $[8,20-22,56,57,62-66])$, but the latter was comparable to a recent meta-analysis [67].

The clinical significance of pterygospinous and pterygoalar ligamentous mineralisation arises from their capacities to form barriers to surgical access as well as their close relationship to neural structures. Although both ligaments are in close proximity anatomically, they are distinct in their courses, most notably posteriorly, with the pterygospinous ligament (a thickening of the interpterygoid aponeurosis) attaching to the spine of the sphenoid and the pterygoalar ligament (a thickening of the lateral interpterygoid or pterygotemporomaxillary aponeurosis) attaching more laterally to the undersurface of the sphenoid [22]. Furthermore, whilst both ligaments attach to the lateral pterygoid plate anteriorly, the pterygoalar ligament attaches more superiorly, at the level of the root [20]. This is particularly relevant for access to the foramen ovale for percutaneous rhizotomy or cavernous sinus biopsy where a mineralised pterygoalar ligament can create a wall-like barrier lateral to the foramen ovale, making percutaneous access difficult or even impossible, particularly via a trans-zygomatic approach $[1,21,51,64,66,76]$. In addition, mineralisation of either ligament may impede trans-zygomatic exploration of the external skull base as well as the parapharyngeal or retropharyngeal spaces $[21,60]$.

Following the descent of the mandibular division of the trigeminal nerve through the foramen ovale, it undergoes branching. Some of these pass through the foramina created by the mineralised pterygospinous and pterygoalar ligaments. In particular, branches to the tensors tympani and veli palatini and medial pterygoid can pass through the foramen of Civinini and motor branches to the temporal, buccinator lateral pterygoid, and sometimes masseter muscles may pass through the foramen created by the pterygoalar ligament [7, 20, 22]. However, the association with neural branches is variable; indeed, von Lüdinghausen et al. described four potential branching patterns $(\mathrm{A}-\mathrm{D})$ in relation to a mineralised pterygospinous ligament with lateral displacement of the branches to the temporalis, masseter, and pterygoid muscles being most common and medial displacement of the branches being least common [60]. Others have described further variations, such as division of the lingual nerve into an anterior and posterior division by a mineralised ligament, which can increase the risk of entrapment [77]. Entrapment may also arise when the lingual nerve passes between an ossified pterygospinous ligament and the medial pterygoid muscle [9, $67,78]$. In addition, Krmpotić-Nemanić et al. noted that 
various types of lateral pterygoid plate enlargement (including complete ossification of the pterygospinous ligament) resulted in the displacement of the lingual and inferior alveolar branches resulting in fixation and increased risk of compression [7]. It is also suggested that a mineralised pterygospinous ligament may potentially cause the compression of other branches of the mandibular nerve (auriculotemporal nerve in particular), leading to periauricular sensory or parotid glandular secretomotor symptoms $[64,66,76]$.

\section{Limitations}

Whilst noncontrast CT provides excellent delineation of mineralised structures, it does not allow for the detailed visualisation of soft tissue anatomy such as nerves and blood vessels that may be affected by ligamentous mineralisation. In the future, MRI may be useful in determining the precise relationships between mineralised ligaments and local cranial nerves. In addition, given the retrospective nature of the study, only limited clinical data was available; therefore, it is not known whether any of the cases included suffered symptoms in relation to ligamentous mineralisation.

\section{Conclusion}

The presence of ligamentous skull base mineralisation is a relatively common phenomenon on CT. These structures can present barriers to minimally invasive surgical access to the infratemporal fossa and increase the risk of neurovascular injury at the central skull base. Furthermore, ligamentous mineralisation has been implicated in neural entrapment. Therefore, knowledge of these structures is of great importance to avoid undesirable complications.

\section{Abbreviations}

CT: Computed tomography; ICA: Internal carotid artery; PACS: Picture archiving and communication system

\section{Funding}

None.

\section{Availability of data and materials}

The datasets generated and/or analysed during the current study are not publicly available in accordance with local data protection policies, but anonymised data are available from the corresponding author on reasonable request.

\section{Authors' contributions}

PT and SH were involved in the conception, design, acquisition, analysis of data, and drafting of the manuscript. AO was involved in the design, analysis, and drafting of the manuscript. FC was involved in the data acquisition and conception. SEJC was involved in the design, conception, analysis, and drafting of the manuscript. All authors read and approved the final manuscript.

\section{Ethics approval and consent to participate}

Institutional approval was obtained and the need for consent waived.

Consent for publication

Not applicable.

\section{Competing interests}

The authors declare that they have no competing interests.

\section{Publisher's Note}

Springer Nature remains neutral with regard to jurisdictional claims in published maps and institutional affiliations.

\section{Author details}

'Department of Radiology, Guy's and St. Thomas' NHS Foundation Trust, 2nd Floor Tower Wing, Guy's Hospital, Great Maze Pond, London SE1 9RT, UK. ${ }^{2}$ Department of Radiology, University of Washington Medical Center, 1959 NE Pacific St, Seattle, WA 98195, USA. ${ }^{3}$ Department of Neuroradiology, King's College Hospital NHS Trust, Denmark Hill, Brixton, London SE5 9RS, UK.

${ }^{4}$ School of Biomedical Engineering and Imaging Sciences Clinical Academic Group, King's College London, King's Health Partners, Guy's Hospital, London, UK.

Received: 4 February 2019 Accepted: 4 April 2019

Published online: 21 May 2019

\section{References}

1. Chouké KS (1949) Injection of mandibular nerve and gasserian ganglion: an anatomic study. Am J Surg 78(1):80-85.

2. Ota N, Tanikawa R, Miyazaki T et al (2015) Surgical microanatomy of the anterior clinoid process for paraclinoid aneurysm surgery and efficient modification of extradural anterior clinoidectomy. World Neurosurg 83(4): 635-643.

3. Miller C, Chamoun R, Beahm D (2016) Morphometric analysis of the middle clinoid process using maxillofacial computed tomography scans. Oper Neurosurg 13(1):1.

4. Lieber S, Wang W-H, Nunez M, et al (2018) The Dural architecture of the cavernous sinus' anterior roof and clinoid space: microsurgical anatomy and technical nuances for Intracavernous and Perisellar endoscopic surgery. J Neurol Surg Part B Skull Base 79(S 01):S1-S188.

5. Sharma A, Rieth GE, Tanenbaum JE et al (2018) A morphometric survey of the parasellar region in more than 2700 skulls: emphasis on the middle clinoid process variants and implications in endoscopic and microsurgical approaches. J Neurosurg 129(1):60-70.

6. Fernandez-Miranda JC, Tormenti M, Latorre F, Gardner P, Snyderman C (2012) Endoscopic endonasal middle clinoidectomy. Oper Neurosurg 71(2 Suppl Operative):ons233-ons239.

7. Krmpotić-Nemanić J, Vinter I, Hat J, Jalsovec D (1999) Mandibular neuralgia due to anatomical variations. Eur Arch Otorhinolaryngol 256(4):205-208.

8. Peker T, Karaköse M, Anil A, Turgut HB, Gülekon N (2002) The incidence of basal sphenoid bony bridges in dried crania and cadavers: their anthropological and clinical relevance. Eur J Morphol 40(3):171-180.

9. Peuker ET, Fischer G, Filler TJ (2001) Entrapment of the lingual nerve due to an ossified pterygospinous ligament. Clin Anat 14(4):282-284.

10. Nakagawa Y, Toda M, Shibao S, Yoshida K (2017) Delayed and isolated oculomotor nerve palsy following minor head trauma. Surg Neurol Int 8:20.

11. Özgür A, Esen K (2015) Ossification of the petrosphenoidal ligament: multidetector computed tomography findings of an unusual variation with a potential role in abducens nerve palsy. Jpn J Radiol 33(5):260-265.

12. Keyes JEL (1935) Observations on four thousand optic foramina in human skulls of known origin. Arch Ophthalmol 13(4):538-568.

13. Ozdogmus O, Saka E, Tulay C, Gurdal E, Uzun I, Cavdar S (2003) Ossification of interclinoid ligament and its clinical significance. Neuroanatomy 2:25-27.

14. Natsis K, Piagkou M, Lazaridis N, Totlis T, Anastasopoulos N, Constantinidis J (2018) Incidence and morphometry of sellar bridges and related foramina in dry skulls: their significance in middle cranial fossa surgery. J CranioMaxillofacial Surg 46(4):635-644.

15. Marom A (2011) A new look at an Old Canal. Skull Base 21(01):053-058.

16. Inal M, Muluk NB, Burulday $V$ et al (2016) Investigation of the calcification at the petroclival region through multi-slice computed tomography of the skull base. J Cranio-Maxillofacial Surg 44(4):347-352.

17. Ambekar S, Sonig A, Nanda A (2012) Dorello's canal and Gruber's ligament: historical perspective. J Neurol Surg B Skull Base 73(6):430-433.

18. Kimball D, Kimball H, Matusz P, Tubbs RS, Loukas M, Cohen-Gadol AA (2015) Ossification of the posterior petroclinoid dural fold: a cadaveric study with neurosurgical significance. J Neurol Surg B Skull Base 76(4):272-277. 
19. Skrzat J, Mroz I, Marchewka J (2012) Bridges of the sella turcica - anatomy and topography. Folia Med Cracov 52(3-4):97-101.

20. Chouké KS (1946) On the incidence of the foramen of civinini and the porus crotaphitico-buccinatorius in American Whites and Negroes. I. Observations on 1544 skulls. Am J Phys Anthropol 4(2):203-226.

21. Ryu S-J, Park M-K, Lee U-Y, Kwak H-H (2016) Incidence of pterygospinous and pterygoalar bridges in dried skulls of Koreans. Anat Cell Biol 49(2):143.

22. Lepp FH, Sandner MO (1968) Anatomic-radiographic study of ossified pterygospinous and "innominate" ligaments. Oral Surg Oral Med Oral Pathol 26(2):244-260

23. Cederberg RA, Benson BW, Nunn M, English JD (2003) Calcification of the interclinoid and petroclinoid ligaments of sella turcica: a radiographic study of the prevalence. Orthod Craniofacial Res 6(4):227-232.

24. Lowry R (2018) VassarStats: website for statistical computation.

25. Liberati A, Altman DG, Tetzlaff J et al (2009) The PRISMA statement for reporting systematic reviews and meta-analyses of studies that evaluate health care interventions: explanation and elaboration. PLoS Med 6(7): e1000100

26. Archana R, Anita R, Jyoti C, Punita M, Rakesh D (2010) Incidence of osseous interclinoid bars in Indian population. Surg Radiol Anat 32(4):383-387.

27. Boyan N, Ozsahin E, Kizilkanat E, Tekdemir I, Soames R, Oguz O (2011) Surgical importance of the morphometry of the anterior clinoid process, optic strut, caroticoclinoid foramen, and interclinoid osseous bridge. Neurosurg Q 21(2):133-136.

28. Brahmbhatt RJ, Bansal M, Mehta C, Chauhan KB (2015) Prevalence and dimensions of complete sella turcica bridges and its clinical significance. Indian J Surg 77(Suppl 2):299-301.

29. Dagtekin A, Avci E, Uzmansel D et al (2014) Regional microsurgical anatomy and variations of the anterior clinoid process. Turk Neurosurg 24(4):484-493.

30. Efthymiou E, Thanopoulou V, Kozompoli D et al (2018) Incidence and morphometry of caroticoclinoid foramina in Greek dry human skulls. Acta Neurochir 160(10):1979-1987.

31. Erturk M, Kayalioglu G, Govsa F (2004) Anatomy of the clinoidal region with special emphasis on the caroticoclinoid foramen and interclinoid osseous bridge in a recent Turkish population. Neurosurg Rev 27(1):22-26.

32. Gibelli D, Cellina M, Gibelli S et al (2018) Sella turcica bridging and ossified carotico-clinoid ligament: correlation with sex and age. Neuroradiol J 31(3): 299-304.

33. Gupta N, Ray B, Ghosh S (2005) A study on anterior clinoid process and optic strut with emphasis on variations of caroticoclinoid foramen. Nepal Med Coll J 7(2):141-144.

34. Kapur E, Mehić A (2012) Anatomical variations and morphometric study of the optic strut and the anterior clinoid process. Bosn J Basic Med Sci 12(2):88.

35. Lee HY, Chung IH, Choi BY, Lee KS (1997) Anterior clinoid process and optic strut in Koreans. Yonsei Med J 38(3):151.

36. Suprasanna K, Kumar A (2017) Surgically relevant bony anatomical variations in paraclinoid aneurysms-three-dimensional multi-detector row computed tomography-based study. J Neurosci Rural Pract 8(3):330

37. Aggarwal B, Gupta M, Kumar H (2012) Ossified ligaments of the skull. J Anat Soc India 61(1):37-40.

38. Gupta V, Khandelwal N, Mathuria SN, Das PJ (2013) Calcified interclinoid ligament: an unusual cause of misinterpretation on cerebral CT angiography. Clin Radiol 68(7):e426-e428.

39. Kucia A, Jankowski T, Siewniak M et al (2014) Sella turcica anomalies on lateral cephalometric radiographs of Polish children. Dentomaxillofacial Radiol 43(8):20140165.

40. Leonardi R, Barbato E, Vichi M, Caltabiano M (2006) A sella turcica bridge in subjects with dental anomalies. Eur J Orthod 28(6):580-585.

41. Marşan G, Öztaş E (2009) Incidence of bridging and dimensions of sella turcica in class I and III Turkish adult female patients. World J Orthod 10(2): 99-103.

42. Scribante A, Sfondrini MF, Cassani M, Fraticelli D, Beccari S, Gandini P (2017) Sella turcica bridging and dental anomalies: is there an association? Int J Paediatr Dent 27(6):568-573.

43. Skrzat J, Mróz I, Spulber A, Zarzecki M, Walocha J (2017) Ossification of the petrosphenoid ligament - a case study. Folia Med Cracov 57(2):87-94.

44. Joo W, Yoshioka F, Funaki T, Rhoton AL (2012) Microsurgical anatomy of the abducens nerve. Clin Anat 25(8):1030-1042.

45. Icke C, Ozer E, Arda N (2010) Microanatomical characteristics of the petrosphenoidal ligament of gruber. Turk Neurosurg 20(3):323-327.
46. Ozdede M, Kayadugun A, Ucok O, Altunkaynak B, Ilkay P (2018) The assessment of maxillofacial soft tissue and intracranial calcifications via cone-beam computed tomography. Curr Med Imaging Rev 14:798.

47. Patwardhan MA (2015) Isolated unilateral oculomotor nerve neuropraxia following a trivial fall in a patient with calcified posterior petroclinoid ligament. Asian J Neurosurg 10(1):56.

48. Sedghizadeh PP, Nguyen M, Enciso R (2012) Intracranial physiological calcifications evaluated with cone beam CT. Dentomaxillofacial Radiol 41(8): 675-678.

49. Skrzat J, Walocha JA, Jaworek JK, Mróz I (2007) The clinical significance of the petroclinoid ligament. Folia Morphol (Warsz) 66(1):39-43.

50. Wysiadecki G, Haładaj R, Polguj M, Żytkowski A, Topol M (2018) Bilateral extensive ossification of the posterior Petroclinoid ligament: an anatomical case report and literature review. J Neurol Surg Part A Cent Eur Neurosurg. 30:236-244.

51. Goyal N, Jain A (2016) An anatomical study of the pterygospinous bar and foramen of Civinini. Surg Radiol Anat 38(8):931-936.

52. Shivanni SS, Yuvaraj BK (2016) An anatomical study of occurrence of pterygospinous bar in Indian skulls. Res J Pharm Technol 9(8):1166-1168.

53. Yadav A, Kumar V, Niranjan R (2014) Pterygospinous bar and foramen in the adult human skulls of North India: its incidence and clinical relevance. Anat Res Int 2014:286794.

54. Saran RS, Ananthi KS, Subramaniam A, Balaji MT, Vinaitha D, Vaithianathan G (2013) Foramen of Civinini: a new anatomical guide for maxillofacial surgeons. J Clin Diagn Res 7(7):1271-1275.

55. Shinde VS, Mallikarjun M, Patil R (2011) A study on an ossified pterygospinous ligament. J Clin Diagn Res 5(5):978-979.

56. Tubbs RS, May WR, Apaydin N et al (2009) Ossification of ligaments near the foramen ovale: an anatomic study with potential clinical significance regarding transcutaneous approaches to the skull base. Neurosurgery 65(6 SUPPL. 1):ons60-ons64.

57. Antonopoulou M, Piagou M, Anagnostopoulou S (2008) An anatomical study of the pterygospinous and pterygoalar bars and foramina - their clinical relevance. J Cranio-Maxillofacial Surg 36(2):104-108.

58. Nayak SR, Saralaya V, Prabhu LV, Pai MM, Vadgaonkar R, D'Costa S (2007) Pterygospinous bar and foramina in Indian skulls: incidence and phylogenetic significance. Surg Radiol Anat 29(1):5-7.

59. Das S, Paul S (2007) Ossified pterygospinous ligament and its clinical implications. Bratisl Lek Listy 108(3):141-143.

60. von Lüdinghausen M, Kageyama I, Miura M, AlKhatib M (2006) Morphological peculiarities of the deep infratemporal fossa in advanced age. Surg Radiol Anat 28(3):284-292.

61. Tebo HG (1968) The pterygospinous bar in panoramic roentgenography. Oral Surg Oral Med Oral Pathol 26(5):654-657.

62. Chouké KS (1947) On the incidence of the foramen of Civinini and the porus crotaphitico-buccinatorius in American whites and negroes; observations on 2745 additional skulls. Am J Phys Anthropol 5(1):79-86.

63. Shaw JP (1993) Pterygospinous and pterygoalar foramina: a role in the etiology of trigeminal neuralgia? Clin Anat 6(3):173-178.

64. Kamath K, Kuberappa V (2014) Anatomical study of pterygospinous and pterygoalar bar in human skulls with their phylogeny and clinical significance. J Clin Diagn Res 8(9):AC10-AC13.

65. Rosa RR, Faig-Leite H, Faig-Leite FS, Moraes LC, Moraes MEL, Filho EM (2010) Radiographic study of ossification of the pterygospinous and pterygoalar ligaments by the Hirtz axial technique. Acta Odontol Latinoam 23(1):63-67.

66. Natsis K, Piagkou M, Skotsimara G et al (2014) The ossified pterygoalar ligament: an anatomical study with pathological and surgical implications. J Cranio-Maxillofacial Surg 42(5):e266-e270.

67. Pękala PA, Henry BM, Pękala JR et al (2017) The pterygoalar bar: a metaanalysis of its prevalence, morphology and morphometry. J CranioMaxillofacial Surg 45(9):1535-1541.

68. Iwasawa T, Iwasaki K, Sawada T et al (2006) Pathophysiological role of endothelin in ectopic ossification of human spinal ligaments induced by mechanical stress. Calcif Tissue Int 79(6):422-430.

69. Camarda AJ, Deschamps C, Forest D (1989) I. Stylohyoid chain ossification: a discussion of etiology. Oral Surg Oral Med Oral Pathol 67(5):508-514.

70. Whitehead MT, Oh C, Raju A, Choudhri AF (2015) Physiologic pineal region, choroid plexus, and dural calcifications in the first decade of life. AJNR Am J Neuroradiol 36(3):575-580.

71. Iseda K (2014) Complex Dolenc procedure: how to deal with ossified interclinoid bars. J Neurol Surg Part B Skull Base 75(S 02):a173. 
72. Manjima S, Naik Z, Keluskar V, Bagewadi A (2015) Multiple jaw cystsunveiling the Gorlin-Goltz syndrome. Contemp Clin Dent 6(Suppl 1): S102-S105.

73. Sundareswaran S, Nipun CA (2015) Bridging the gap: sella turcica in unilateral cleft lip and palate patients. Cleft Palate-Craniofac J 52(5):597-604.

74. Tubbs RS, Sharma A, Loukas M, Cohen-Gadol AA (2014) Ossification of the petrosphenoidal ligament: unusual variation with the potential for abducens nerve entrapment in Dorello's canal at the skull base. Surg Radiol Anat 36(3):303-305.

75. Standefer M, Bay JW, Dohn DF (1982) Trigeminal neuralgia secondary to a tentorial ossification: a case report. Neurosurgery. 11(4):527-529.

76. Piagkou M, Demesticha T, Piagkos G, Georgios A, Panagiotis S (2010) Lingual nerve entrapment in muscular and osseous structures. Int J Oral Sci 2(4): 181-189.

77. Erdogmus S, Pinar Y, Celik S (2009) A cause of entrapment of the lingual nerve: ossified pterygospinous ligament - a case report. Neuroanatomy. 8: 43-45.

78. Nayak SR, Rai R, Krishnamurthy A et al (2008) An unusual course and entrapment of the lingual nerve in the infratemporal fossa. Bratisl Lek Listy 109(11):525-527.

\section{Submit your manuscript to a SpringerOpen ${ }^{\circ}$ journal and benefit from:}

- Convenient online submission

- Rigorous peer review

- Open access: articles freely available online

- High visibility within the field

- Retaining the copyright to your article

Submit your next manuscript at $\boldsymbol{\wedge}$ springeropen.com 